\title{
Signaling Complex Organization by PDZ Domain Proteins
}

\author{
J ing-Song Fan Mingjie Zhang \\ Department of Biochemistry, Hong Kong University of Science and Technology, Kowloon, Hong Kong, PR China
}

\section{Key Words}

PDZ domains · Scaffolding · Signal transduction • Domain organization

\begin{abstract}
As one of the most abundant protein domains in the genomes of metazoans, PDZ domains play important roles in the targeting of proteins to specific cell membranes, as well as assembling proteins into supramolecular signaling complexes. The structures of individual PDZ domains, along with their diverse cooccurrence with a great variety of other protein domains, provide the biochemical basis for the functional diversity of PDZ proteins. In this review, we first briefly summarize the structure and target-binding properties of PDZ domains. After surveying the SMART protein domain database, we attempt to classify PDZ domain proteins into three general categories. We end the review by presenting several recent studies showing some novel features of PDZ domain proteins.
\end{abstract}

Copyright $\odot 2003$ S. Karger AG, Basel

PDZ domains are globular protein interaction modules that play central roles in organizing signal transduction complexes and specialized membrane structures. These domains were first identified from consensus sequences of $\sim 90$ amino acid residues of three proteins: the

\begin{tabular}{ll}
\hline KARGER & ( 2003 S. Karger AG, Basel \\
1424-862X/02/0116-0315\$19.50/0 \\
$\begin{array}{l}\text { Fax +4161306 12 34 } \\
\text { E-Mail karger@karger.ch } \\
\text { www.karger.com }\end{array}$ & $\begin{array}{l}\text { Accessible online at: } \\
\text { www.karger.com } / \mathrm{nsg}\end{array}$
\end{tabular}

postsynaptic density PSD-95/SAP90, the Drosophila septate junction protein disc-large, and the tight junction protein ZO-1. PDZ domains were also referred to as DHR (DLG homology region) or the GLGF repeat (after a signature Gly-Leu-Gly-Phe sequence in the domain) at an early stage in the literature. Today, it is known that PDZ domains are among the most abundant protein domains in the multicellular eukaryotic genomes. Analysis of the genome sequences of Caenorhabditis elegans, Drosophila and humans estimates the presence of 89,128 , and 320 PDZ domain-containing proteins, respectively. The number of PDZ domains is significantly larger than these numbers in each genome, as many PDZ proteins contain multiple PDZ domains (see below) [1, 2]. Although the majority of PDZ proteins do not contain transmembrane domains, PDZ proteins are often associated with the cellular membrane. This association with the cell membrane enables PDZ proteins to organize localized protein complexes for signal transduction purposes [3-5]. Another general function of PDZ proteins is to organize/maintain large and complicated cellular structures such as cell-cell junctions $[6,7]$.

\section{Structures and Target Binding of PDZ Domains}

The topic of the structural and target-binding properties of PDZ domains was covered in a number of recent excellent reviews [5,8-11], and we will only provide a

\footnotetext{
Mingjie Zhang

Department of Biochemistry, Hong Kong University of Science and Technology Clear Water Bay

Kowloon, Hong Kong (PR China)

Tel. +868522358 8709, Fax +868522358 1552, E-Mail mzhang@ust.hk
} 


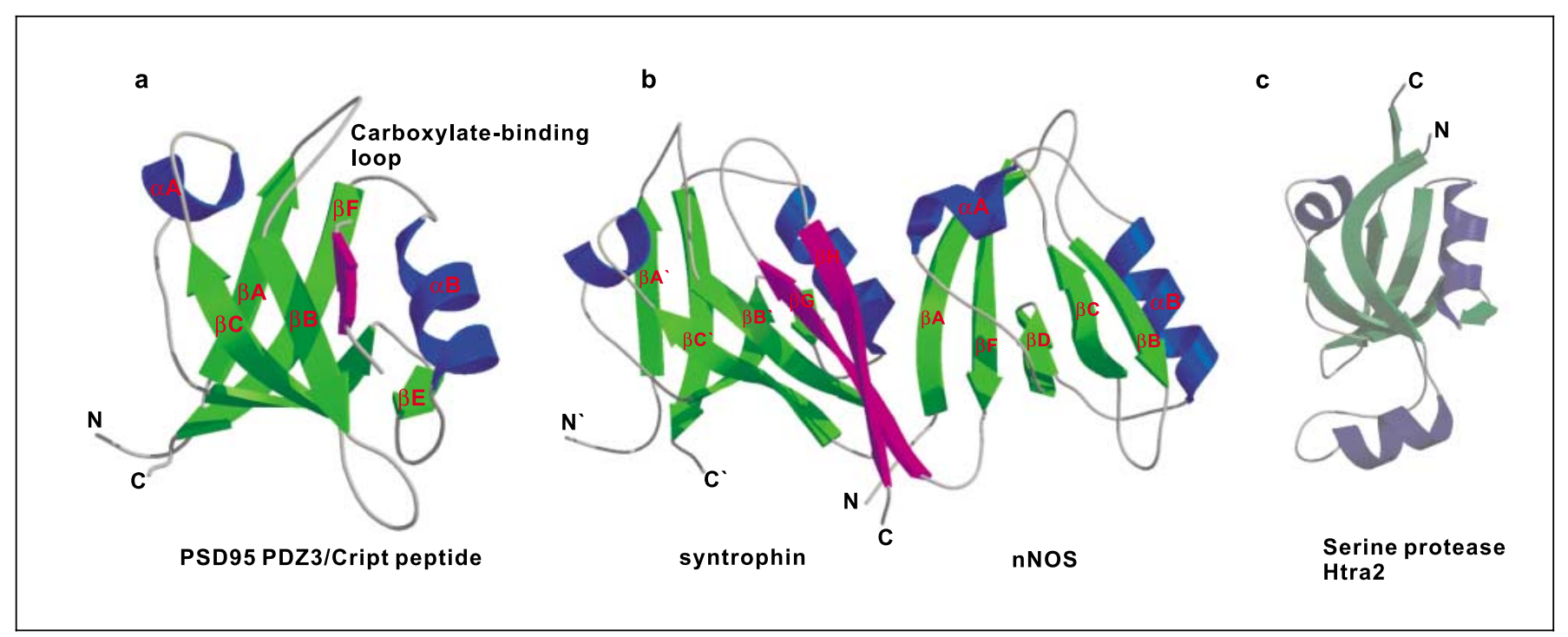

Fig. 1. Three-dimensional structures of $P D Z$ domains in ribbon diagram representations. a The crystal structure of the third PDZ domain of PSD-95 in complex with a target peptide (in magenta) from the protein CRIPT [13], showing the structure and carboxyl peptide binding of a canonical PDZ domain. $\mathbf{b}$ The three-dimensional structure of the syntrophin/nNOS PDZ dimer, showing the binding of a PDZ domain to an internal peptide sequence [17]. The structure also highlights the mechanism of head-to-tail, PDZ domain-mediated dimerization. c The structure of the PDZ domain from mitochondrial serine protease HtrA2, showing the structure of an unconventional PDZ domain [47]. Note that the structure of the HtrA2 PDZ domain is permuted relative to the PDZ domains shown in $\mathbf{a}$ and $\mathbf{b}$.

brief summary of this area. The structures of a number of canonical PDZ domains, both in free and target-bound forms, have been determined by X-ray crystallographic and/or NMR spectroscopic techniques [12-25]. PDZ domains fold into compact globular structure comprising a six-stranded $\beta$-barrel flanked by two $\alpha$-helices (fig. 1a). Peptide ligands from the extreme carboxyl termini of target proteins bind to a groove formed by the second $\alpha$-helix $(\alpha \mathrm{B})$ and the second $\beta$-strand $(\beta \mathrm{B})$ of the PDZ domains. The carboxyl peptides augment the $\beta B$ strand in an antiparallel fashion (fig. 1a). Amino acid residues at the 0 and -2 positions of the carboxyl peptide play dominant roles in the peptide's binding to a cognate PDZ domain, although residues at the -1 and -3 positions and those at further upstream positions also contribute to the binding $[22,23,26,27]$. The uneven distribution of PDZ domain proteins as well as their binding partners provides a spatial regulation to the binding specificity of the interactions in vivo.

In addition to binding to carboxyl peptides, PDZ domains can also interact with internal short peptide fragments in target proteins $[16,17,28-30]$. The best example of this type of interaction is heterodimer formation be- tween PDZ domains of nNOS and PSD-95 or syntrophin $[16,17,29,30]$. The nNOS PDZ domain contains an additional two-stranded $\beta$-sheet (referred to as $\beta$-finger) at the C-terminal end of the canonical PDZ domain, and this $\beta$-finger structure inserts into the $\alpha \mathrm{B} / \beta \mathrm{B}$ groove of the syntrophin/PSD-95 PDZ domain [17, 30] (fig. 1b). Mutational studies showed that a preformed $\beta$-finger structure is essential for the nNOS PDZ domain to bind to PSD$95 /$ syntrophin $[30,31]$. It is likely that the interaction between a PDZ domain and an internal peptide sequence depended on the specific amino acid sequence as well as the defined conformation of the peptide fragment. Due to the high stringency, the interaction between PDZ domain and internal sequences is likely to be less common. The studies of the interaction between nNOS and PSD-95/ syntrophin provide a mechanistic understanding of PDZ domain-mediated oligomerization of PDZ domain proteins. However, it remains to be tested whether such a head-to-tail PDZ domain assembly is a general mechanism for PDZ domain-mediated oligomerization observed in a number of PDZ domain proteins [32-36]. 


\section{Domain Organization of PDZ-Containing Proteins}

Inspection of $\sim 1,250 \mathrm{PDZ}$ proteins documented in the SMART database (http://SMART.embl-heidelberg. de) reveals that PDZ domains are organized in a variety of ways with other protein domains at the primary sequence level. In this review, we attempt to categorize the PDZ proteins into three general classes based on their organization properties (fig. 2).

Class I: PDZ Domain Proteins with No Intrinsic

Enzyme Activities

This class of PDZ proteins either does not contain any recognizable catalytic domains or has enzyme-like domains, but they lack detectable catalytic activities. This class of PDZ proteins can be further divided into two subclasses.

Class I-1: PDZ Domain-Only Proteins. A striking feature of this class of PDZ proteins is that these proteins contain only PDZ domains and no other recognizable protein domains. For example, InaD is composed of 5 PDZ domains, and MUPP1 contains as many as 13 PDZ domains (fig. 2). If each PDZ domain binds to a specific target, one would expect that these multiple PDZ domain proteins will be able to assemble a number of interacting proteins. Therefore, these multiple PDZ domain proteins can function as scaffolds for protein complex assembly in cells. The scaffolding capacity of these multi-PDZ proteins is further expanded by oligomerization of the scaffold protein itself [reviewed in 9, 10]. The best-studied example of PDZ domain-mediated signaling complex assembly is the InaD-mediated photoreception in Drosophi$l a$ [reviewed in 3, 4]. Each of 5 PDZ domains of InaD binds to a specific partner in the fly phototransduction cascade; InaD is, therefore, capable of assembling the multiple signaling components into a 'transducisome' in the rhabdomere of photoreceptor cells [36, 37]. The confinement of signaling proteins onto a single scaffold protein InaD is ideally suited for the remarkably fast (milliseconds) photoreceptive response and adaptation processes in the fly. Mutation of InaD leads to mislocalization of a number of proteins (e.g., PKC and PLC), and the mutant fly is nearly blind $[3,4]$.

Class I-2: PDZ Domain together with Other Protein Modules. PDZ domains are found to frequently appear together with other protein domains without detectable enzyme activities. This class of PDZ proteins includes the founding member of the PDZ protein PSD-95. PSD-95 is a prototype of MAGUK (membrane-associated guanylate kinase) family proteins, which contain one to three PDZ domains followed by an $\mathrm{SH} 3$ domain and a guanylate kinase-like (GK) domain. The GK domain of MAGUKs has lost its catalytic activity during evolution, and evolved to be a protein-binding module [38-40]. MAGUKs have been shown to play critical roles in organizing signal complexes in neuronal synapses $[5,8]$. In addition to being together with various protein interaction domains such as PTB, LIM, L27 and SH3 domains, PDZ domains also occur in proteins with lipid interaction domains including PH, C2 and PX domains (fig. 2). The cooccurrence of PDZ domains together with other protein-protein and/or protein-lipid interaction domains confers versatile organizational capacities on these scaffold proteins.

\section{Class II: PDZ Domain Proteins Containing}

Enzymatic Activities

In contrast to the proteins in class I, the class II PDZ proteins contain one or at most two catalytic domains. It seems that various types of enzymatic domains can coexist with PDZ domains. For example, PDZ domains can occur in both protein kinases and phosphatases. Tyrosine phosphatase 1E contains 5 PDZ domains, and the PDZ domains may act as docking sites for various substrates of the enzyme [41, 42]. Neuronal nitric oxide contains a PDZ domain at the N-terminal end of the enzyme, and the function of the PDZ domain is to physically target the enzyme to the NMDA receptor by binding to the PDZ domain of PSD-95 in synapses, thereby the enzyme can be activated in a timely fashion by the NMDA receptormediated $\mathrm{Ca}^{2+}$ influx [43].

A large number of PDZ proteins in this class contain enzymatic domains that can regulate $G$ protein signaling pathways. For example, various GEF (guanine-nucleotide exchange factor) domains are often associated with PDZ domains. PDZ proteins are often found to contain RGS (regulator of heteromeric $G$ protein signaling) domains. The recently identified PDZ-RGS3 protein is particularly interesting [44]. The PDZ domain of PDZ-RGS3 binds to the C-terminal tail of EphB, and the RGS domain of the protein regulates the GTPase activity of CXCR4, thereby linking the EphB reverse signaling and the G protein couple receptor signaling pathways.

\section{Class III: Unconventional PDZ Domain Proteins}

Amino acid sequence analysis identified a distinct family of 'PDZ-like' domain-containing proteins in plants, bacteria as well as metazoans [45]. At the amino acid sequence level, these 'PDZ-like' domains share significantly lower homology with the canonical PDZ do- 
Class I: PDZ proteins without intrinsic enzymatic activities

I-1: PDZ domain only proteins

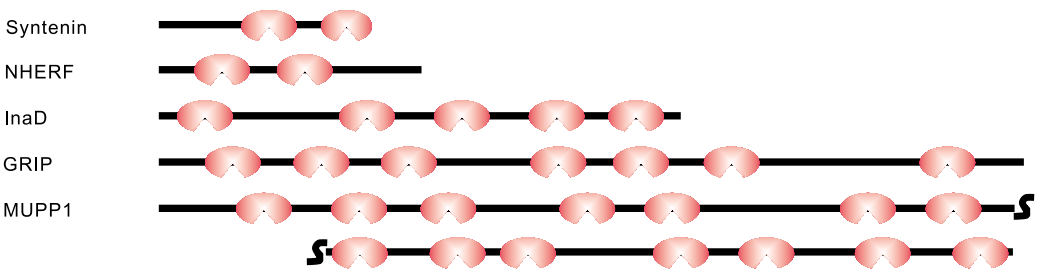

I-2: PDZ domain with other modules

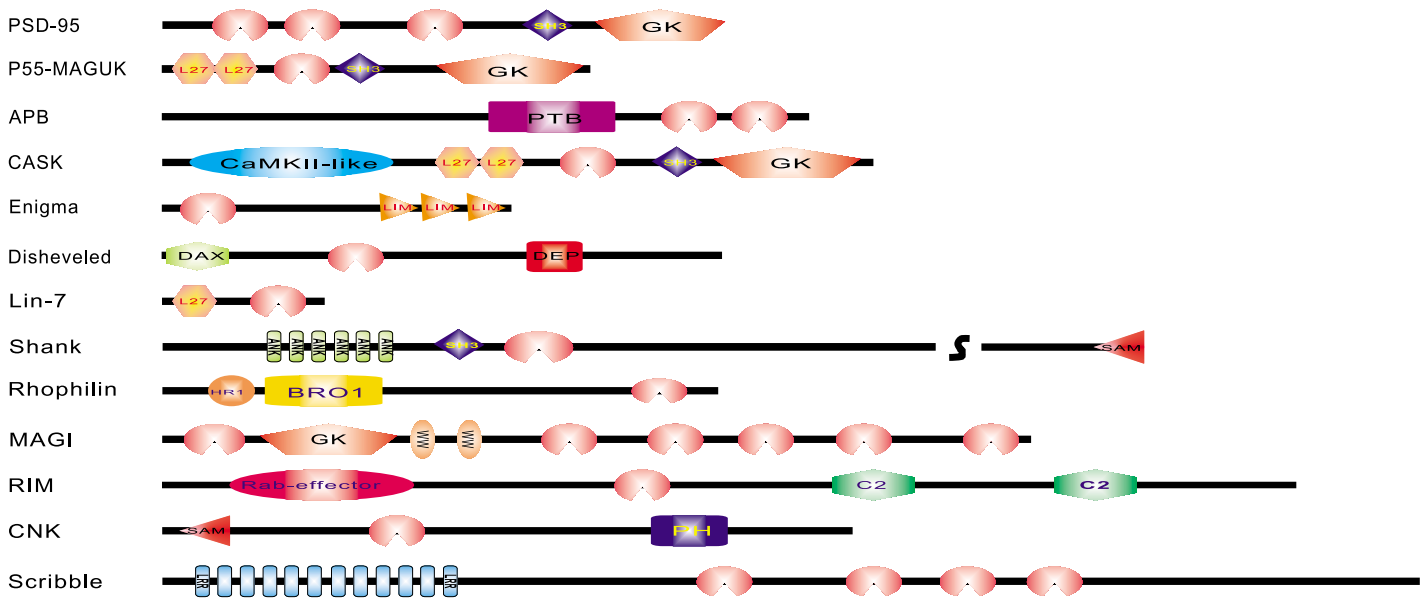

Class II: PDZ proteins that containenzymatic activities

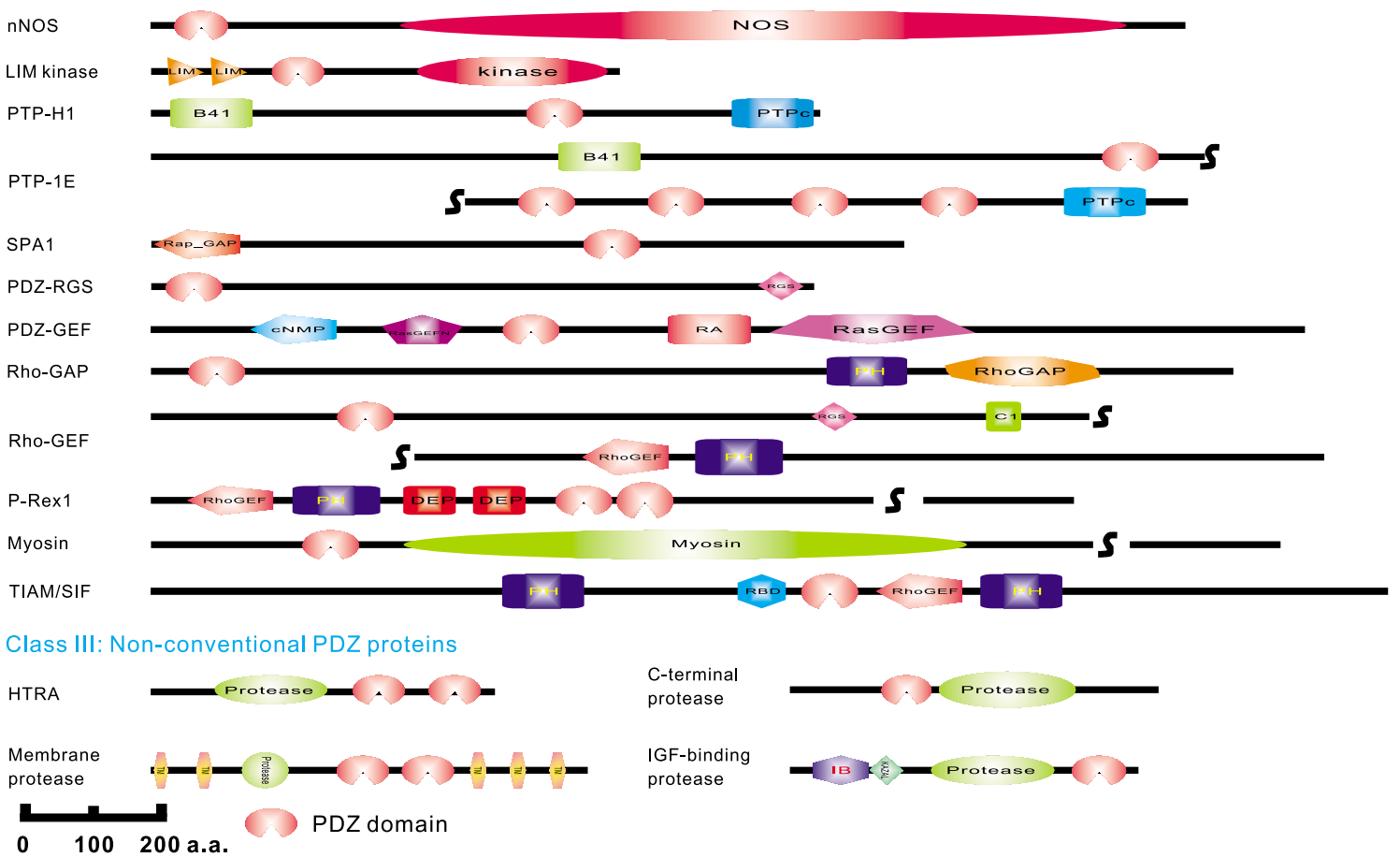

2 
mains. A signature feature of this family of 'PDZ-like' domain proteins is that the PDZ domains often coexist with various protease domains (fig. 2). Recent crystal structures of three members of this protein family have shown that these 'PDZ-like' domains indeed fold into a three-dimensional structure highly similar to that of the canonical PDZ domains [46-48] (fig. 1c). However, there is a striking difference in their topologies between the protease PDZ domains and the canonical PDZ domains. In the protease PDZ domain, a stretch of amino acid residues at the $\mathrm{C}$-terminal end of the domain forms a $\beta$-strand structure and occupies the $\beta$ A strand position in the canonical PDZ domains (a topology arrangement called circular permutation). The conformation of the $\alpha \mathrm{B} / \beta \mathrm{B}$ groove (the nomenclature of the canonical PDZ domains) of each PDZ domain suggests that the protease PDZ domains can also bind to carboxyl peptides as canonical PDZ domains do [46-48]. In fact, the PDZ2 domain of bacterial HtrA/DegP has an internal peptide fragment bound to the $\alpha \mathrm{B} / \beta \mathrm{B}$ groove [48]. An interesting aspect of the HtrA structures is the direct regulatory roles played by PDZ domains on the catalytic activities of the protease. The PDZ domains can directly interact with the catalytic domain, thereby denying the substrate access to the active site of the enzyme [47, 48]. An attractive working hypothesis is that the PDZ domain acts as the protease substrate

Fig. 2. Domain organization of PDZ proteins. The number of amino acid residues in each protein is indicated in scale by the length of the black line. The detected protein domains (as defined by SMART [55]) are indicated by their names. The abbreviated names of the domains are: $\mathrm{SH} 3=$ Src homology 3 domain; GK = guanylatekinase-like domain; L27 = Lin-2, Lin-7 domain; $\mathrm{PTB}=$ protein tyrosine-binding domain; CaMKII-like $=$ calmodulin-dependent kinase II like domain; LIM = zinc-binding domain present in Lin-11, Isl-1, Mec-3; DAX = disheveled and axin-homology domain; DEP = disheveled, Egl-10 and pleckstrin-homology domain; ANK = ankyrin repeats; SAM = sterile alpha motif; HR1 = protein kinase $\mathrm{C}$-related kinase homology region 1 homologues; BRO1 = Bro-1-like domain; $\mathrm{WW}=$ domain with 2 conserved Trp residues; $\mathrm{RAB}$ effector $=\mathrm{C} 2$, protein kinase $\mathrm{C}$-conserved region $2 ; \mathrm{PH}=$ pleckstrin-homology domain; LRR = leucine-rich repeats; NOS = nitric oxide synthase; $\mathrm{B} 41=$ band 4.1 homology domain PTPc $=$ protein tyrosine phosphatase, catalytic domain; Rap-GAP = rap/ran-GTPase-activating protein homology domain; RGS = regulator of $G$ protein signaling domain; $\mathrm{cNMP}=$ cyclic nucleotide-monophosphate-binding domain; RasGEFN = guanine nucleotide exchange factor for Ras-like GTPases N-terminal motif; RA $=$ Ras association domain; RasGEF $=$ Ras-like guanine nucleotide exchange factor; RhoGAP = Rho-like GTPase activator protein; $\mathrm{C} 1=$ protein kinase $\mathrm{C}$ conserved region 1 domain; $\mathrm{RBD}=$ Raf-like Ras-binding domain; $\mathrm{TM}=$ transmembrane domain; IB = insulin-like growth factor-binding domain; $\mathrm{KAZAL}=$ Kazal-type serine protease inhibitors (or regulatory factor) docking site. Binding of the substrates (or regulatory factors) displaces the inhibitory PDZ domains from the active site of the enzyme and leads to the activation of the proteases. It will be interesting to see whether a similar PDZ domain-mediated regulatory strategy is also used in the enzymes containing canonical PDZ domains described in class II PDZ proteins.

\section{Novel Aspects of PDZ Structure and Function from Recent Studies}

Structural and functional studies in the past few years uncovered several novel features of PDZ domains. In this review, we describe several examples.

\section{PDZ Domains as Lipid-Binding Modules}

A recent study by Zimmermann et al. [49] prompted a rethinking of the current concept of PDZ domains as protein interaction modules. In addition to binding to carboxyl peptides, Zimmermann et al. found that the PDZ domains in a number of proteins including syntenin and CASK can bind to phosphatidylinositol phosphate, and the binding constant between syntenin PDZ1 and lipids is comparable to well-characterized lipid-binding domains such as $\mathrm{PH}$ and $\mathrm{C} 2$ domains. The authors further showed that the PDZ1 of syntenin selectively binds to phosphatidylinositol 4,5-biphosphate $\left(\mathrm{PIP}_{2}\right)$. Binding competition experiments using syndecan carboxyl peptide indicated that $\mathrm{PIP}_{2}$ is likely to occupy the same carboxyl peptidebinding groove of the PDZ domain. The study raises the interesting possibility that PDZ domains contain an intrinsic membrane localization capacity that is independent of binding to receptor tails. It is not known whether lipid binding is a general property of PDZ domains. We tested a number of PDZ domains including PDZ domains from PSD-95 and GRIP, and failed to detect significant binding to various lipids (unpubl. observation).

\section{Tandem PDZ Repeats Function Synergistically in Binding to Targets}

A noticeable feature in multiple PDZ domain proteins is that PDZ domains are often grouped in tandem repeats. For example, PDZ1, 2 of PSD-95 are connected by a short linker of 5 amino acids. The two PDZ domains of syntenin are linked by a 4-residue connecting sequence. PDZ13 and PDZ4-6 of GRIP are grouped together. Emerging evidence indicate that these grouped PDZ domains can function synergistically in binding to target proteins [5052]. Binding of syntenin PDZ2 to carboxyl peptides from 
syndecan and ephrin-B1 is positively regulated by PDZ1 [51]. In return, syntenin PDZ1-mediated lipid binding is cooperatively regulated by PDZ2 [49]. PDZ4 of GRIP can directly influence folding of PDZ5, thereby regulating its binding to AMPA receptors [52]. PDZ12 of PSD-95 binds to dimeric ligands with considerably higher affinity than the individual PDZ domains. A recent structural and biochemical study of PSD-95 PDZ12 showed that the two PDZ domains have limited freedom of rotation and their C-terminal peptide-binding grooves are aligned with each other with an orientation preference for binding to pairs of C-termini extending from multimeric membrane proteins [unpubl. observation]. These studies suggested that such tandemly arranged protein-protein interaction modules are not just a simple attachment of 'beads' on a 'string', but may represent functional 'supermodules' spatially organized for coordinated binding to specific targets.

\section{Unusual PDZ Domain-Mediated Interaction}

It is well accepted that PDZ domain-mediated protein target interactions involve the $\alpha \mathrm{B} / \beta \mathrm{B}$ groove of $\mathrm{PDZ}$ domains. However, we recently discovered that PDZ7 of GRIP can bind to its target using a surface entirely different from the $\alpha \mathrm{B} / \beta \mathrm{B}$ groove of the domain. GRIP PDZ7 was found to interact with a RasGEF protein called GRASP-1 [53]. The interaction between GRIP and GRASP-1 is rather unusual as GRASP-1 does not contain the carboxyl PDZ-binding motif or a PDZ-like domain. The three-dimensional structure solved by NMR spectroscopy showed that of GRIP PDZ7 contains a large, solvent exposed hydrophobic surface composed of residues from the $\beta \mathrm{E}$ strand, the $\alpha \mathrm{B}$ helix and the loop connecting the two secondary structural elements. It was shown that GRIP PDZ7 interacts with GRASP-1 via this hydrophobic surface [54]. This study uncovered a novel mode of PDZ domain-mediated protein-protein interaction. It will be interesting to test whether other atypical PDZ domainmediated interactions also follow a mechanism similar to that observed in the GRIP PDZ7/GRASP-1 complex.

\section{Conclusion}

Recent studies using genetic and molecular approaches have firmly established that PDZ domain proteins play important roles in assembling protein complexes for signal transduction and organizing large, complicated cellular structures in asymmetric cells such as neurons and epithelial cells. Biochemical and structural studies have provided mechanistic insights into the interaction between PDZ domains and their target proteins. Many questions remain to be answered. For example, how do several hundred PDZ domains control their target-binding specificities inside cells? Do PDZ domains influence each other in the multi-PDZ domain proteins? Where are the PDZ domain protein-mediated signaling complexes assembled/disassembled? Are these signaling complexes dynamically regulated? If yes, how? Another interesting area for future study is to develop specific small molecular weight compounds to intervene between PDZ domainmediated protein interactions. The use of such compounds may result in potential therapeutic applications regarding various PDZ domain-related human diseases.

\section{Acknowledgments}

We thank Dr. Andrew Miller for careful reading of the manuscript. Research in MZ's laboratory is partially supported by grants from the Research Grants Council of Hong Kong and the Human Frontier Science Program.

\section{References}

1 Schultz J, Milpetz F, Bork P, Ponting CP: SMART, a simple modular architecture research tool: Identification of signaling domains. Proc Natl Acad Sci USA 1998;95:58575864.

2 Letunic I, Goodstadt L, Dickens NJ, Doerks T, Schultz J, Mott R, Ciccarelli F, Copley RR, Ponting CP, Bork P: Recent improvements to the SMART domain-based sequence annotation resource. Nucleic Acids Res 2002;30:242244.

3 Montell C: Visual transduction in Drosophila. Annu Rev Cell Dev Biol 1999; 15:231-268.

4 Tsunoda S, Zuker CS: The organization of INAD-signaling complexes by a multivalent PDZ domain protein in Drosophila photore- ceptor cells ensures sensitivity and speed of signaling. Cell Calcium 1999;26:165-171.

5 Garner CC, Nash J, Huganir RL: PDZ domains in synapse assembly and signalling. Trends Cell Biol 2000;10:274-280.

6 Fanning AS, Anderson JM: PDZ domains: Fundamental building blocks in the organization of protein complexes at the plasma membrane. J Clin Invest 1999;103:767-772.

7 Bilder D: PDZ proteins and polarity: Functions from the fly. Trends Genet 2001;17:511519.

8 Craven SE, Bredt DS: PDZ proteins organize synaptic signaling pathways. Cell 1998;93: 495-498.
9 Harris BZ, Lim WA: Mechanism and role of PDZ domains in signaling complex assembly. J Cell Sci 2001;114:3219-3231.

10 Sheng M, Sala C: PDZ domains and the organization of supramolecular complexes. Annu Rev Neurosci 2001;24:1-29.

11 Hung AY, Sheng M: PDZ domains: Structural modules for protein complex assembly. J Biol Chem 2002;277:5699-5702.

12 Morais Cabral JH, Petosa C, Sutcliffe MJ, Raza S, Byron O, Poy F, Marfatia SM, Chishti AH, Liddington RC: Crystal structure of a PDZ domain. Nature 1996;382:649-652.

13 Doyle DA, Lee A, Lewis J, Kim E, Sheng M, MacKinnon R: Crystal structures of a complexed and peptide-free membrane protein- 
binding domain: Molecular basis of peptide recognition by PDZ. Cell 1996;85:1067-1076.

14 Daniels DL, Cohen AR, Anderson JM, Brunger AT: Crystal structure of the hCASK PDZ domain reveals the structural basis of class II PDZ domain target recognition. Nat Struct Biol 1998;5:317-325.

15 Schultz J, Hoffmuller U, Krause G, Ashurst J, Macias MJ, Schmieder P, Schneider-Mergener $\mathrm{J}$, Oschkinat $\mathrm{H}$ : Specific interactions between the syntrophin PDZ domain and voltage-gated sodium channels. Nat Struct Biol 1998;5:1924

16 Tochio H, Zhang Q, Mandal P, Li M, Zhang M: Solution structure of the extended neuronal nitric oxide synthase PDZ domain complexed with an associated peptide. Nat Struct Biol 1999;6:417-421.

17 Hillier BJ, Christopherson KS, Prehoda KE, Bredt DS, Lim WA: Unexpected modes of PDZ domain scaffolding revealed by structure of nNOS-syntrophin complex. Science 1999; 284:812-815.

18 Tochio H, Hung F, Li M, Bredt DS, Zhang M: Solution structure and backbone dynamics of the second PDZ domain of postsynaptic density-95. J Mol Biol 2000;295:225-237.

19 Kozlov G, Gehring K, Ekiel I: Solution structure of the PDZ2 domain from human phosphatase hPTP1E and its interactions with Cterminal peptides from the Fas receptor. Biochemistry 2000;39:2572-2580.

20 Karthikeyan S, Leung T, Birrane G, Webster G, Ladias JA: Crystal structure of the PDZ1 domain of human $\mathrm{Na}(+) / \mathrm{H}(+)$ exchanger regulatory factor provides insights into the mechanism of carboxyl-terminal leucine recognition by class I PDZ domains. J Mol Biol 2001;308 963-973.

21 Karthikeyan S, Leung T, Ladias JA: Structural basis of the $\mathrm{Na}^{+} / \mathrm{H}^{+}$exchanger regulatory factor PDZ1 interaction with the carboxyl-terminal region of the cystic fibrosis transmembrane conductance regulator. J Biol Chem 2001;276: 19683-19686.

22 Kimple ME, Siderovski DP, Sondek J: Functional relevance of the disulfide-linked complex of the N-terminal PDZ domain of InaD with NorpA. EMBO J 2001;20:4414-4422.

23 Kozlov G, Banville D, Gehring K, Ekiel I: Solution structure of the PDZ2 domain from cytosolic human phosphatase hPTP1E complexed with a peptide reveals contribution of the beta2-beta3 loop to PDZ domain-ligand interactions. J Mol Biol 2002;320:813-820.

24 Karthikeyan S, Leung T, Ladias JA: Structura determinants of the $\mathrm{Na}^{+} / \mathrm{H}^{+}$exchanger regulatory factor interaction with the beta 2 adrenergic and platelet-derived growth factor receptors. J Biol Chem 2002;277:18973-18978.

25 Piserchio A, Pellegrini M, Mehta S, Blackman SM, Garcia EP, Marshall J, Mierke DF: The PDZ1 domain of SAP90. Characterization of structure and binding. J Biol Chem 2002;277. 6967-6973

26 Songyang Z, Fanning AS, Fu C, Xu J, Marfatia SM, Chishti AH, Crompton A, Chan AC, Anderson JM, Cantley LC: Recognition of unique carboxyl-terminal motifs by distinct PDZ domains. Science 1997;275:73-77.

Signaling Complex Organization by

PDZ Domain Proteins
27 Cai C, Coleman SK, Niemi K, Keinanen K: Selective binding of SAP97 to GluR-A AMPA receptor subunit is determined by a novel sequence motif. J Biol Chem 2002;277:3148431490

28 Gee SH, Sekely SA, Lombardo C, Kurakin A, Froehner SC, Kay BK: Cyclic peptides as noncarboxyl-terminal ligands of syntrophin PDZ domains. J Biol Chem 1998;273:2198021987.

29 Christopherson KS, Hillier BJ, Lim WA, Bredt DS: PSD-95 assembles a ternary complex with the N-methyl- $D$-aspartic acid receptor and a bivalent neuronal NO synthase PDZ domain. J Biol Chem 1999;274:27467-27473.

30 Tochio H, Mok YK, Zhang Q, Kan HM, Bredt DS, Zhang M: Formation of nNOS/PSD-95 PDZ dimer requires a preformed beta-finger structure from the nNOS PDZ domain. J Mol Biol 2000;303:359-370.

31 Harris BZ, Hillier BJ, Lim WA: Energetic determinants of internal motif recognition by PDZ domains. Biochemistry 2001;40:59215930.

32 Dong H, O'Brien RJ, Fung ET, Lanahan AA, Worley PF, Huganir RL: GRIP: A synaptic PDZ domain-containing protein that interacts with AMPA receptors. Nature 1997;386:279284

33 Srivastava S, Osten P, Vilim FS, Khatri L, Inman G, States B, Daly C, DeSouza S, Abagyan R, Valtschanoff JG, Weinberg RJ, Ziff EB: Novel anchorage of GluR2/3 to the postsynaptic density by the AMPA receptor-binding protein ABP. Neuron 1998;21:581-591.

34 Fouassier L, Yun CC, Fitz JG, Doctor RB: Evidence for ezrin-radixin-moesin-binding phosphoprotein 50 (EBP50) self-association through PDZ-PDZ interactions. J Biol Chem 2000;275:25039-25045.

35 Lin D, Edwards AS, Fawcett JP, Mbamalu G, Scott JD, Pawson T: A mammalian PAR-3PAR-6 complex implicated in Cdc42/Racl and a PKC signalling and cell polarity. Nat Cell Biol 2000;2:540-547.

$36 \mathrm{Xu} \mathrm{XZ,} \mathrm{Choudhury} \mathrm{A,} \mathrm{Li} \mathrm{X,} \mathrm{Montell} \mathrm{C:} \mathrm{Coor-}$ dination of an array of signaling proteins through homo- and heteromeric interactions between PDZ domains and target proteins. J Cell Biol 1998;142:545-555.

37 Tsunoda S, Sierralta J, Sun Y, Bodner R, Suzuki E, Becker A, Socolich M, Zuker CS: A multivalent PDZ-domain protein assembles signalling complexes in a G-protein-coupled cascade. Nature 1997;388:243-249.

38 Kim E, Naisbitt S, Hsueh YP, Rao A, Rothschild A, Craig AM, Sheng M: GKAP, a novel synaptic protein that interacts with the guanylate kinase-like domain of the PSD-95/SAP90 family of channel clustering molecules. J Cell Biol 1997;136:669-678.

39 Brenman JE, Topinka JR, Cooper EC, McGee AW, Rosen J, Milroy T, Ralston HJ, Bredt DS: Localization of postsynaptic density-93 to dendritic microtubules and interaction with microtubule-associated protein 1A. J Neurosci 1998; 18:8805-8813.

40 Pak DT, Yang S, Rudolph-Correia S, Kim E, Sheng M: Regulation of dendritic spine morphology by SPAR, a PSD-95-associated RapGAP. Neuron 2001;31:289-303.
41 Cuppen E, Gerrits H, Pepers B, Wieringa B, Hendriks W: PDZ motifs in PTP-BL and RIL bind to internal protein segments in the LIM domain protein RIL. Mol Biol Cell 1998;9: 671-683.

42 Palmer A, Zimmer M, Erdmann KS, Eulenburg V, Porthin A, Heumann R, Deutsch U, Klein R: EphrinB phosphorylation and reverse signaling. Regulation by Src kinases and PTPBL phosphatase. Mol Cell 2002;9:725-737.

43 Brenman JE, Chao DS, Gee SH, McGee AW, Craven SE, Santillano DR, Wu Z, Huang F, Xia H, Peters MF, Froehner SC, Bredt DS Interaction of nitric oxide synthase with the postsynaptic density protein PSD-95 and alphal-syntrophin mediated by PDZ domains. Cell 1996;84:757-767.

44 Lu Q, Sun EE, Klein RS, Flanagan JG: Ephrin$B$ reverse signaling is mediated by a novel PDZ-RGS protein and selectively inhibits $G$ protein-coupled chemoattraction. Cell 2001; 105:69-79.

45 Ponting CP: Evidence for PDZ domains in bacteria, yeast, and plants. Protein Sci 1997;6: 464-468.

46 Liao DI, Qian J, Chisholm DA, Jordan DB, Diner BA: Crystal structures of the photosystem II D1 C-terminal processing protease. Nat Struct Biol 2000;7:749-753.

47 Li W, Srinivasula SM, Chai J, Li P, Wu JW, Zhang Z, Alnemri ES, Shi Y: Structural insights into the pro-apoptotic function of mitochondrial serine protease HtrA2/Omi. Nat Struct Biol 2002;22:22.

48 Krojer T, Garrido-Franco M, Huber R, Ehrmann M, Clausen T: Crystal structure of DegP (HtrA) reveals a new protease-chaperone machine. Nature 2002;416:455-459.

49 Zimmermann P, Meerschaert K, Reekmans G Leenaerts I, Small JV, Vandekerckhove J, David G, Gettemans J: PIP(2)-PDZ domain binding controls the association of syntenin with the plasma membrane. Mol Cell 2002;9:12151225.

50 Raghuram V, Mak DO, Foskett JK: Regulation of cystic fibrosis transmembrane conductance regulator single-channel gating by bivalent PDZ-domain-mediated interaction. Proc Natl Acad Sci USA 2001;98:1300-1305.

51 Grootjans JJ, Reekmans G, Ceulemans H, David G: Syntenin-syndecan binding requires syndecan-synteny and the co-operation of both PDZ domains of syntenin. J Biol Chem 2000; 275:19933-19941.

52 Zhang Q, Fan J-S, Zhang M: Interdomain chaperoning between PSD-95, Dlg, and Zo-1 (PDZ) domains of glutamate receptor-interacting proteins. J Biol Chem 2001;276:43216-43220.

53 Ye B, Liao D, Zhang X, Zhang P, Dong H, Huganir RL: GRASP-1:A neuronal RasGEF associated with the AMPA receptor/GRIP complex. Neuron 2000;26:603-617.

54 Feng W, Fan J-S, Jiang M, Shi Y-W, Zhang M: PDZ7 of glutamate receptor interacting protein binds to its target via a novel hydrophobic surface area. J Biol Chem 2002;277:41140-41146.

55 Schultz J, Copley RR, Doerks T, Ponting CP, Bork P: SMART: A web-based tool for the study of genetically mobile domains. Nucleic Acids Res 2000;28:231-234. 